\title{
Development of Dispatching Strategy for Inbound and Outbound Trucks in Cross Docking System
}

\author{
Wooyeon $\mathrm{Yu}^{*} \cdot$ Pius J. Egbelu** \\ ${ }^{*}$ Department of Industrial and Management Engineering College of Engineering \\ Myong Ji University \\ ${ }^{* *}$ School of Management New Jersey Institute of Technology
크로스도킹 시스템에서의 입고 및 출하 트럭의 배차 전략 개발
유 우 연** 파이어스 애그밸루**
*명지대학교 산업경영공학과 • ${ }^{* *}$ 뉴저지 기술원

\begin{abstract}
A cross docking operation involves multiple inbound trucks that deliver items from suppliers to a distribution center and multiple outbound trucks that ship items from the distribution center to customers. Based on customer demands, an inbound truck may have its items transferred to multiple outbound trucks. Similarly, an outbound truck can receive its consignments from multiple inbound trucks. The objective of this study is to find the best truck spotting sequence for both inbound and outbound trucks in order to minimize total operation time of the cross docking system under the condition that multiple visits to the dock by a truck to unload or load its consignments is allowed. The allocations of the items from inbound trucks to outbound trucks are determined simultaneously with the spotting sequences of both the inbound and outbound trucks.
\end{abstract}

Key Words: Cross Docking, Distribution Center, Makespan, Dock, Inbound Truck, Outbound Turck

\section{INTRODUCTION}

The application of cross-docking technique to streamline and enhance the efficiency of supply chain networks is growing. Cross docking is a material handling and distribution concept in which incoming items to a warehouse are moved directly from receiving docks to shipping docks, without being held at a distribution center [1]. The growing application of cross docking systems is motivated by the pressure to improve customer service and cut supply chain operation costs through the reduction or elimination of inventory, storage tasks, and order picking. Improved customer service comes through improved responsiveness to customer needs and increased accuracy in product shipments. Reduced inventory and warehousing costs are achieved by the elimination of product storage and order picking at the warehouse.

Quick order turnaround time is a key performance measure for cross docking systems. While turnaround time is influenced by such factors as product availability, product sortation, and product preparation, a major contributor to order turnaround time is the length of time it takes to process all inbound and outbound trucks in a day.

† Corresponding Author : Wooyeon Yu, Department of Industrial and Management Engineering College of Engineering Myong Ji University,San 38-2, Nam-Dong, Cheoin-Gu, Yongin Gyeonggi-Do, S.Korea 449-728 M • P : 82-31-330-6455, E-mail: wyyuie@mju.ac.kr Received March 14, 2013; Revision Received June 12, 2013; Accepted June 5, 2013. 
As is often the case, not all inbound (outbound) trucks can be scheduled for unloading (loading) at the same time since docks constitute a limited resource.

How well the inbound and outbound trucks are scheduled and managed at the docks influence the length of time the cross docking operation can be completed and how quickly shipments can leave the warehouse. Since the set of products delivered by an inbound truck may transfer to any number of outbound trucks and vice versa, the best truck scheduling arrangement is one that synchronizes the unloading and loading of inbound and outbound trucks such that the number of times an item is handled from receiving to shipping is minimized. The more items are handled, the more material handling time would be involved and the longer it would take to complete the cross docking operation. Therefore, the scheduling of the inbound trucks and the outbound trucks at the docks to minimize total cross docking operation time would improve responsiveness to customers while at the same time minimize operation cost.

The objective of this study is to find the best truck spotting sequences for both inbound and outbound trucks to minimize total operation time of the cross docking system in situations where a truck can visit and leave the docks any number of times until the truck's service needs are met. The allocations of the products from inbound trucks to outbound trucks are determined simultaneously with the spotting sequences of the inbound and outbound trucks.

\section{LITERATURE REVIEW}

As cross docking is a comparatively new logistics strategy, the scientific research on cross docking has been studied recently. The scientific research on cross docking can be grouped as the following categories: i) cross docking network design including the decision of cross docking facilities locations ([2], [3], [4], [5]), ii) design of the cross docking facilities ([6], [7], [8]), iii) assignments of trucks to dock doors ([9], [10], [11]), iv) scheduling of trucks in cross docking systems ([1], [12], [13], [14], [15], [16],
[17]), and v) other general matter of cross docking system ([18], [19], [20], [21]).

As can be seen above, scheduling of trucks in cross docking systems are one of the most active research areas studied on cross docking systems in recent years. This problem decides on the succession of inbound and outbound trucks at a given set of dock doors of the distribution center. On the basis of the truck schedule, each inbound and outbound truck arriving at the distribution center is assigned to a specific dock door where shipments are processed. This research also belongs to the fourth category, scheduling of trucks in cross docking systems. Therefore, in this section, we are mainly going to introduce the technical papers whose topics are related to the truck scheduling problem in cross docking systems.

Yu and Egbelu [1] studied on the best truck docking or scheduling sequence for both inbound and outbound trucks to minimize total operation time when a temporary storage buffer is located at the shipping dock. The product assignment to trucks and the docking sequences of the inbound and outbound trucks are all determined simultaneously. To address problem, they developed a mixed integer programming model and a heuristic algorithm. Soltani and Sadjadi [14], Vahdani and Zandieh [15], and Arabani et al. [16] are all studied on the same problem as Yu and Egbelu [1]. Soltani and Sadjadi [14] proposed two hybrid meta-heuristics - hybrid simulated annealing and hybrid variable neighborhood search - to solve the best sequence of inbound and outbound trucks in order to minimize the total flow time of the cross docking system. The Taguchi method was applied to demonstrate the robustness of their algorithms. Vahdani and Zandieh [15] developed five meta-heuristic algorithms - genetic algorithm (GA), tabu search (TS), simulated annealing (SA), electromagnetism-like algorithm (EMA) and variable neighbourhood search (VNS) - to schedule the trucks in cross-dock systems such that minimize total operation time. The proposed procedure is based on the response surface methodology (RSM).

They recommended VNS algorithm for scheduling trucks in cross-docking systems. Arabani et al. [16] addressed five meta-heuristics - genetic algorithm 
(GA), tabu search(TS), particle swarm optimization (PSO), ant colony optimization(ACO) and differential evolution(DE) - to find the best sequence of inbound and outbound trucks. According to their study, the GA, PSO, ACO, and DE algorithms have a relatively similar behavior in acquiring the best objective function, makespan.

Chen and Song [12] proposed a mixed integer programming and four heuristics to minimize the makespan of the two-stage hybrid cross docking scheduling problem. Their heuristics are based on Johnson's rule and dynamic Johnson's rule to determine the scheduling sequence in first stage, and ready time and LPT rule to determine the scheduling sequence in second stage. Boysen [13] studied a special truck scheduling problem arising in the cross docks of the food industry. The problem is formalized such that three different operational objectives, such as the flow time, processing time and tardiness of outbound trucks, are minimized. To solve the resulting truck scheduling problem, he applied an exact dynamic programming approach and a heuristic simulated annealing procedure. His computational tests showed that the developed simulated annealing procedure was appropriate to solve problem instances of real-world size. Larbi et al. [17] studied the transshipment scheduling problem in a cross dock under the availability of three different levels of information on the inbound site. Based on the availability of information, they developed three policies. In the first policy, they assume to have complete information on the order of arrivals and the contents of all inbound trucks and developed an optimal graph based model to solve it. The second and the third policies assume the availability of partial and no information on the sequence of upcoming trucks and developed heuristics for each policy. More researches about truck scheduling problem in cross docking systems can be found in Boysen and Fliedner [22].

\section{MODEL DESCRIPTION}

The general characteristics of the cross docking systems studied in this research are alike that presented by Yu and Egbelu [1] except inbound and outbound trucks can make repeat vistis to docks. The cross docking systems studied in this paper operates as follows. Inbound trucks arrive at the receiving docks and unload products onto the receiving dock. An inbound truck, after unloading products bound for an outbound truck at the shipping dock, may i) choose to continue unloading other products bound for other outbound trucks not yet at the dock and have the additional products sent to the temporary storage or ii) pull out of the dock and return again at a later time to unload all or some of the remaining products. An inbound truck may pull intermittently in and out of the receiving dock one or more times until all its unloading needs are satisfied.

In the mean time, unloaded products from an inbound truck move from the receiving dock to the shipping dock on a conveyor. This research does not consider operations inside the distribution center such as scanning, sorting operations, etc. Therefore, the arrival sequence of the products at the shipping dock is the same as their unloading sequence at the receiving dock. If a product arriving at the shipping dock is not intended for loading into the outbound truck currently at the dock, the product is stored in the temporary storage until the appropriate outbound truck comes into the shipping dock. Finally, outbound trucks load products from shipping docks and depart the shipping docks. The operation mode of an inbound truck can be similarly applied to outbound trucks. This occurs when an outbound truck loads some of its needed products from a certain inbound truck or from the temporary storage and no other products currently at the shipping dock or the next arriving batch of products are destined for the current outbound truck. Then, the current outbound truck either waits until its needed products arrive at the shipping dock or is allowed to move out from the shipping dock and another outbound truck is sent to the shipping dock to load its needed products.

In addition to the operational conditions described above, the following assumptions also apply: i) all inbound and outbound trucks are available at time zero, ii) the total number of inbound units of a 
product equals the total number of outbound units for the product, and iii) there is one receiving dock and and one shipping dock. The following information is assumed to be known beforehand: i) the product types and the number of units of each product loaded in an inbound truck, ii) the product types and the number of units of each product type needed by an outbound truck, iii) units of time required to load and unload one unit of product, iv) transfer time of products from receiving dock to shipping dock, and v) truck change time.

The objective of this study is to find the best sequence for truck spotting for both the inbound and outbound trucks to minimize total operation time or makespan. Additionally, the solution would also determine the product routings or the quantity of products transferred between pairs of inbound and outbound trucks. The solution also needs to show whether the products move directly from an inbound truck to an outbound truck or pass through the temporary storage area during the transition.

The mathematical model for the above cross docking problem was developed by $\mathrm{Yu}$ [23], but it could not provide the exact solution even for very small scale instances. Thus, heuristic algorithms based on dispatching strategies for inbound and outbound trucks were developed in this research as alternative. The developed heuristics were able to obtain solutions to the real world problem quickly except that no optimality is guaranteed.

\section{DEVELOPMENT OF HEURISTIC METHODS}

In this cross docking problem, there are two types of delay times. The first type occurs when there is an outbound truck change. The second type occurs when the current outbound truck is held at the dock awaiting its needed products to arrive at the shipping dock. A change of inbound trucks or the unloading of products from an inbound truck and sending the products to the temporary storage may also cause the second type of delay time. For the problem, one of two decisions can be made after an inbound truck has transferred some certain products to a certain outbound truck. The decision is either to have the current inbound truck pull out from the dock for another inbound truck to pull in or hold the current inbound truck at the dock and continue unloading any other remaining products left in the truck for transfer to the temporary storage. Similarly, after a current outbound truck has loaded all of its needed products available at the shipping dock, the truck can pull out from the dock and have another outbound truck pull in to the dock or hold the current outbound truck at the dock until its other needed products arrive from the receiving dock. Depending on the decision made at each decision point, delay time may be incurred to increase the makespan. The heuristic algorithm must be able to choose the schedule that minimizes the increase in the makespan at each decision point.

The heuristic algorithm consists of two phases. In Phase I, the product routing (i.e. which inbound truck transfers which product to an outbound truck) is determined. The initial inbound and outbound truck sequences are also created in Phase I. In the Phase I schedule, no products are sent to temporary storage. In Phase II, a check is made to determine whether the makespan can be decreased by either holding an inbound truck at the dock to continue unloading its products and sending the products to temporary storage or move the vehicle from the dock for another inbound truck to pull in. If a condition that decreases makespan by sending products to temporary storage is found, then the schedule is modified to unload more products from the current inbound truck and move the unloaded products to the temporary storage instead of changing the inbound truck. Phase II is continued until no pair of inbound and outbound truck schedules is found that further decreases the makespan.

The following notations are used in this paper:

$\mathrm{R}$ : Number of inbound trucks,

$\mathrm{S}$ : Number of outbound trucks,

$\mathrm{N}$ : Number of product types,

D : Truck change time; this is the delay incurred in changing between two trucks at a dock,

V : Transfer or travel time of products from the receiving dock to the shipping dock, 
$\mathrm{t}_{\mathrm{i}}^{\mathrm{r}}$ : Inbound truck $\mathrm{i}$,

$\mathrm{t}_{\mathrm{j}}^{\mathrm{s}}$ : Outbound truck $\mathrm{j}$,

$\mathrm{r}^{\prime}{ }_{\mathrm{ik}}$ : Number of units of product type $\mathrm{k}$ which remains to be unloaded from $t_{i}^{r}$ in a given algorithmic iteration,

$s^{\prime}{ }_{j k}$ : Number of units of product type $k$ which remains to be loaded in $t_{j}^{s}$ in a given algorithmic iteration,

$A_{j}^{s}$ : Set of associate inbound trucks for $t_{j}^{s}$. The associate inbound trucks for $t^{s}$ is defined as the sets of inbound trucks that carry enough products to satisfy the requirements of $t^{s}$. Therefore, many associate inbound trucks can exist for a given outbound truck,

$\mathrm{T}^{\mathrm{r}}$ : The ordered set of scheduled inbound trucks,

$\mathrm{T}^{\mathrm{s}}$ : The ordered set of scheduled outbound trucks,

$\mathrm{T}^{\mathrm{p}}$ : The ordered set of product routings information based on the inbound and outbound truck sequences,

$\alpha_{\mathrm{ij}}$ : An element in set $\mathrm{T}^{\mathrm{p}}$ that indicates that there is a transfer of product( $s$ ) from $t_{i}^{r}$ to $t_{j}^{s}$. The $\alpha_{i j}$ is product routing indicator.

$\mathrm{T}^{\mathrm{n}}$ : The ordered set of the units or number of products transferred from an inbound truck to an outbound truck corresponding to the product routing $\alpha_{\mathrm{ij}}$ in $\mathrm{T}^{\mathrm{p}}$. There is a one to one match between element of $\mathrm{T}^{\mathrm{P}}$ and $\mathrm{T}^{\mathrm{n}}$,

$\beta_{\mathrm{ij}}$ : An element of $\mathrm{T}^{\mathrm{n}}$. It is the number of units of products that are transferred from $t_{i}^{r}$ to $t_{j}^{s}$.

$\mathrm{F}^{\mathrm{r}}$ : The ordered set of completion times of the unloading activities associated with the product routings $\alpha_{\mathrm{ij}}$ in set $\mathrm{T}^{\mathrm{p}}$,

$\gamma_{i j}$ : Unloading completion time of $t_{i}$ corresponding to product routing $\alpha_{\mathrm{ij}}$ in set $\mathrm{T}^{\mathrm{p}}$,

$\mathrm{F}^{\mathrm{s}}$ : The ordered set of loading completion times or departure times of the outbound trucks correspon ding to the outbound truck sequence $\mathrm{T}^{\mathrm{s}}$,

$\delta j$ : Loading completion or departure time of $t_{j}^{s_{j}}$ corresponding to the outbound truck sequence in set $\mathrm{T}^{\mathrm{s}}$.

\subsection{Phase I of Heuristic Algorithm}

At each iteration of Phase I, the first step is to find the best associate inbound trucks for each unscheduled outbound truck. Then the outbound truck that has the smallest number of associate inbound trucks is selected as the next scheduled outbound truck because it will minimize delay time for inbound truck changes. The selected outbound truck and its associate inbound trucks are scheduled in the outbound truck sequence and the inbound truck sequence respectively.

Once an outbound truck and its associate inbound trucks are scheduled, the remaining number of products in the inbound trucks is updated by product type. Next, for each unscheduled outbound truck, a new set of its associate inbound trucks is formed from the updated inbound truck list. Again, the outbound truck that has the smallest number of associate inbound trucks is selected and scheduled. Once an outbound truck and its associate inbound trucks are selected and scheduled, the remaining number of product units in the inbound trucks is again updated. The process of selection, scheduling, and updating is continued until all trucks are scheduled. When all inbound and outbound trucks are scheduled, Phase I is terminated and Phase II is started. The algorithmic steps of Phase I are as follows:

\section{STEP 1}

Initialize sets $T^{\mathrm{r}}, \mathrm{T}^{\mathrm{s}}, \mathrm{T}^{\mathrm{p}}$ and $\mathrm{T}^{\mathrm{n}} . \mathrm{T}^{\mathrm{r}}=\varnothing, \mathrm{T}^{\mathrm{s}}=\varnothing$, $\mathrm{T}^{\mathrm{p}}=\varnothing$ and $\mathrm{T}^{\mathrm{n}}=\varnothing$.

\section{STEP 2}

For each unscheduled outbound truck $\mathrm{t}_{\mathrm{j}}^{\mathrm{s}} \notin \mathrm{T}^{\mathrm{s}}$, find its best associate inbound trucks $\mathrm{A}_{\mathrm{j}}^{\mathrm{s}}$ and product routing $\alpha_{\mathrm{ij}}$ where $\mathrm{t}_{\mathrm{i}}^{\mathrm{r}} \in \mathrm{A}_{\mathrm{j}}^{\mathrm{s}}$, using one of the following strategies:

Dispatching Strategy 1 - Maximum flow between the inbound truck and the outbound truck. For each pair of $t_{i}$ and $t_{j}^{s}$, the flow, $\mathrm{m}_{\mathrm{ij}}^{\mathrm{f}}$, is calculated as follows:

$$
m^{f}{ }_{i j}=\sum_{k=1}^{N} \min \left(r_{i k}^{\prime}, s_{j k}^{\prime}\right)
$$

Dispatching Strategy 2 - Maximum ratio between the inbound truck and the outbound truck. For each pair of $t_{i}$ and $t_{j}^{s}$, the ratio, $m_{i j}^{r}$, is calculated as follows: 


$$
\begin{aligned}
& \sum_{k=1}^{N} \min \left(r_{i k}^{\prime}, s_{j k}^{\prime}\right)
\end{aligned}
$$

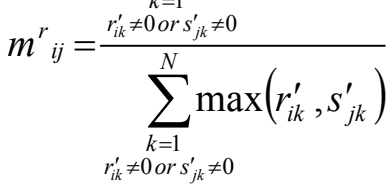

Dispatching Strategy 3 - Maximum fitness between the inbound truck and the outbound truck. For each pair of $t_{i}^{r}$ and $t_{j}^{s}$, the fitness, $m_{i j}^{f t}$, is calculated as follows:

$$
m^{f t}{ }_{i j}=\frac{\sum_{\substack{r_{i j}^{\prime} \neq 0 \text { or } s_{j k}^{\prime} \neq 0 \\ \text { max }}}^{N} \frac{\min \left(r_{i k}^{\prime}, s_{j k}^{\prime}\right)}{\operatorname{man}\left(r_{i k}^{\prime}, s_{j k}^{\prime}\right)}}{\sum_{\substack{k=1 \\ r_{i j}^{\prime} \neq 0 \text { or } s_{j k}^{\prime} \neq 0}}^{N} 1}
$$

The procedure for forming the best associate inbound trucks $\mathrm{A}_{\mathrm{j}}^{\mathrm{s}}$ for an unscheduled outbound truck $t_{j}^{s}$ involves the sequential selection of one of the inbound trucks using one of the above selection criteria at each iteration. After the best inbound truck is selected at each iteration, the remaining quantity of each product yet to be met in the outbound truck is updated. The above procedure is repeated until the outbound truck loads all of its needed products from its best associate inbound trucks.

\section{STEP 3}

Choose the outbound truck that has the smallest number of associate inbound trucks. If there is a tie, choose the outbound truck that needs the largest number of products.

3a Place the selected outbound truck, $\mathrm{t}_{\mathrm{j}}^{\mathrm{s}}$ * at the end of the sequence in set $\mathrm{T}^{\mathrm{s}}$.

$3 \mathrm{~b}$ Schedule the best associate inbound trucks of the selected outbound truck, $\mathrm{A}_{\mathrm{j}}^{\mathrm{S}} *=\left\{\mathrm{t}_{[1]}^{\mathrm{r}}, \mathrm{t}_{[2]}^{\mathrm{r}}, \cdots, \mathrm{t}^{\mathrm{r}}[\mathrm{k}]\right\}$ at the end of sequence in set $\mathrm{T}^{\mathrm{r}}$.

$3 c$ Place the product routing, $\left\{\alpha_{[1]]^{*}}, \alpha_{[2]]^{*}}, \cdots, \alpha_{[\mathrm{k}] \mathrm{j} *}\right\}$ at the end of sequence in set $\mathrm{T}^{\mathrm{y}}$.

3d Place the total number of products transferred corresponding to $\alpha_{[\mathrm{ij} j *}$, where $1 \leq \mathrm{i} \leq \mathrm{k}$, in set $\mathrm{T}^{\mathrm{p}}$ (i.e. $\left.\left\{\beta_{[1]] *}, \beta_{[2] \mathrm{j} *}, \cdots, \beta_{[k \mathrm{k}] *}\right\}\right)$ at the end of sequence in set $T^{\mathrm{n}}$.

\section{STEP 4}

Update the remaining quantities of the products in the inbound trucks. If there is any unscheduled outbound truck, go to Step 2. Otherwise, stop Phase I. The solution for Phase I is found. The solution would yield the following four sequences: i) inbound truck sequence, $\mathrm{T}^{\mathrm{T}}$, ii) outbound truck sequence, $\mathrm{T}^{\mathrm{s}}$, iii) information on product routing, $\mathrm{T}^{\mathrm{p}}$, and iv) total quantity of products transferred from an inbound truck to an outbound truck, $\mathrm{T}^{\mathrm{n}}$.

Go to Phase II. This solution becomes the input to the Phase II algorithm, which is described later.

To illustrate the Phase I algorithm, consider a problem involving five inbound trucks, four outbound trucks and six product types as given in Table 1. Let truck delay or change time equal 20 units of time and product transfer time from the receiving dock to the shipping dock equal 10 units of time. Suppose Dispatching Strategy 1, "Maximum flow between the receiving and outbound trucks," is employed. At the end of Phase I, the complete solution for Phase I is as presented below:
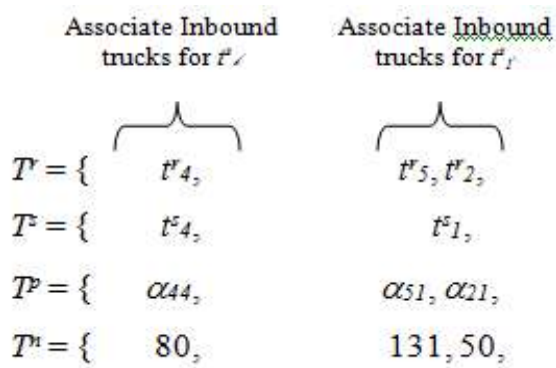

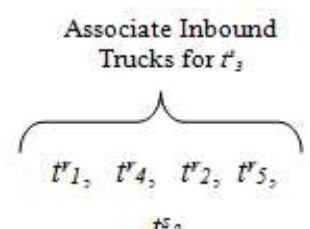

$\alpha_{13,} \alpha_{43}, \alpha_{23}, \alpha_{53}$,

$166,115,51,4$,

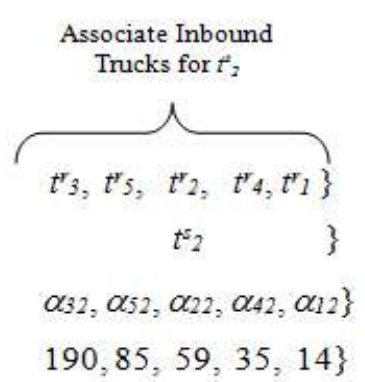


$<$ Table 1> Example Problem to Illustrate Phase I of the Cross Docking Heuristic

\begin{tabular}{|c|c|c|}
\hline \multicolumn{3}{|c|}{ Inbound Truck } \\
\hline Truck & Product & Quantity \\
\hline \multirow{4}{*}{1} & 1 & 14 \\
\cline { 2 - 3 } & 2 & 69 \\
\cline { 2 - 3 } & 3 & 28 \\
\cline { 2 - 3 } & 5 & 69 \\
\hline \multirow{3}{*}{2} & 1 & 50 \\
\cline { 2 - 3 } & 4 & 40 \\
\cline { 2 - 3 } & 6 & 70 \\
\hline \multirow{3}{*}{4} & 2 & 190 \\
\hline \multirow{3}{*}{5} & 1 & 23 \\
\cline { 2 - 3 } & 3 & 115 \\
\hline & 5 & 92 \\
\cline { 2 - 3 } & 3 & 44 \\
\hline \multirow{3}{*}{} & 5 & 66 \\
\hline
\end{tabular}

\subsection{Phase II of Heuristic Algorithm}

In Phase II, a search is carried out to decrease the makespan by sending products to temporary storage when justified instead of changing the inbound trucks. The Phase II algorithm does not change the outbound truck sequence found in Phase I. On the other hand, the rest of the sequences such as the inbound truck sequence (i.e. set $\mathrm{T}^{\mathrm{r}}$ ), the sequence for product routing (i.e. set $\mathrm{T}^{\mathrm{p}}$ ) and the sequence for the number of products transferred (i.e. set $\mathrm{T}^{\mathrm{n}}$ ) are allowed to change if such changes would decrease makespan.

In Phase II, two conditions that can decrease makespan are identified. For the first condition, consider two consecutively scheduled outbound trucks $t_{i}^{s}$ and $t_{j}^{s}$ in the outbound truck sequence and their associate inbound trucks in the inbound truck sequence as given below:

Suppose the two consecutive outbound trucks, $t_{i}^{s}$

Associate Inbound Trucks for $t^{5}$

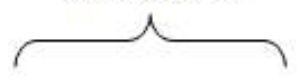

$$
\begin{array}{cc}
T^{r}=\{\ldots, & , \ldots, t_{p}^{r}, \ldots, \\
T^{s}=\{\ldots, & t^{s}{ }_{i,}
\end{array}
$$

\begin{tabular}{|c|c|c|}
\hline \multicolumn{3}{|c|}{ Outbound Truck } \\
\hline Truck & Product & Quantity \\
\hline \multirow{3}{*}{1} & 1 & 50 \\
\cline { 2 - 3 } & 3 & 36 \\
\cline { 2 - 3 } & 6 & 95 \\
\hline \multirow{4}{*}{2} & 2 & 194 \\
\cline { 2 - 3 } & 3 & 53 \\
\cline { 2 - 3 } & 5 & 62 \\
\cline { 2 - 3 } & 6 & 74 \\
\hline \multirow{4}{*}{3} & 1 & 37 \\
\cline { 2 - 3 } & 2 & 65 \\
\cline { 2 - 3 } & 3 & 18 \\
\cline { 2 - 3 } & 4 & 40 \\
\cline { 2 - 3 } & 5 & 165 \\
\hline 4 & 3 & 11 \\
\hline & & 80 \\
\hline
\end{tabular}

and $\mathrm{t}_{\mathrm{j}}^{\mathrm{s}}$, need the same associate inbound truck, $\mathrm{t}_{\mathrm{p}}^{\mathrm{r}}$. It means that the inbound truck trp would need to be scheduled twice at the dock for the two consecutively scheduled outbound trucks. Suppose inbound truck $\mathrm{t}_{\mathrm{p}}^{\mathrm{r}}$ unloads the products needed for outbound truck $t_{j}^{s}$ immediately after it unloads the products needed for outbound truck $\mathrm{t}_{\mathrm{i}}^{\mathrm{s}}$. If this occurs, then the truck changing time for inbound truck $\mathrm{t}_{\mathrm{p}}^{\mathrm{r}}$ is avoided (i.e., saved) because inbound truck $\mathrm{t}_{\mathrm{p}}^{\mathrm{r}}$ only needs to come to the receiving dock once for the two consecutive outbound trucks, $t_{i}^{s}$ and $t_{j}^{s}$. On the other hand, the departure time of outbound truck $t_{i}^{\mathrm{s}}$ may be delayed because outbound truck $t_{i}^{s}$ may need to wait without being loaded with products from another inbound truck because the inbound truck $\mathrm{t}_{\mathrm{p}}^{\mathrm{r}}$ is still occupying the dock unloading products for outbound truck $t^{\mathrm{s}}$. If this occurs, the departure time of outbound truck $t_{i}^{s}$ could be delayed up to or beyond the completion time for unloading the products transferring from trp to $t_{j}^{s}$.

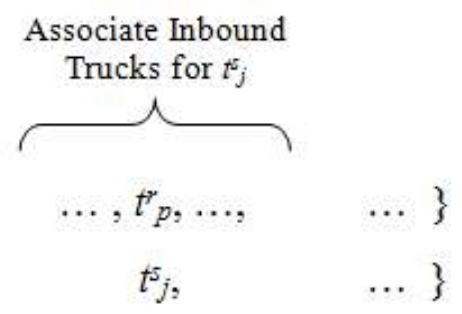


This would increase the makespan by $\beta_{\mathrm{pj}}$ time units, the amount of time required to unload the products transferred to temprorary storage. From the above observation, it can be seen that if two consecutive outbound trucks, $t_{i}^{s}$ and $t_{j}^{s}$, need the same associate inbound truck $\mathrm{t}_{\mathrm{p}}^{\mathrm{r}}$ and the total time required to unload products which transfer from inbound truck $\mathrm{t}_{\mathrm{p}}^{\mathrm{r}}$ to outbound truck $\mathrm{t}_{\mathrm{j}}^{\mathrm{s}}$ is less than the truck change time, then the makespan can be decreased by unloading the products needed for outbound truck $\mathrm{t}_{j}^{\mathrm{s}}$ immediately after unloading the products needed for outbound truck $\mathrm{t}_{\mathrm{i}}^{\mathrm{s}}$.

The second condition for Phase II checks whether the makespan can be decreased by reducing the number of inbound truck changes. To reduce the number of inbound truck changes, inbound trucks that appear more than once in the inbound truck sequence are re-examined. However, reducing the number of repeat visits to the dock by inbound trucks would result in the unloading of additional products that are not needed by the current outbound truck at the dock. Therefore these additional products would have to be sent to temporary storage. Unloading more products not bound to the outbound truck currently at the dock may increase the waiting time of the outbound truck, which in turn may delay the its (i.e. current outbound truck's) departure time. However, makespan can be decreased by decreasing the number of inbound truck changes. In other words, makespan can be decreased when the following condition is satisfied. If the time required to unload products from inbound truck $t_{p}^{r}$ is less than the truck change time, D, and it is not the first appearance of the inbound truck $\mathrm{t}_{\mathrm{p}}^{\mathrm{r}}$ in the inbound truck sequence, then makespan can be decreased by unloading the products at the earlier appearance of inbound truck $\mathrm{t}_{\mathrm{p}}^{\mathrm{r}}$ in the inbound truck sequence.

Based on the above characteristics, two conditions for modifying the schedules in Phase II were developed. The detailed explanation for two conditions applied in Phase II is presented in the following sections.

\subsubsection{Condition 1 applied in Phase II}

Suppose that outbound trucks $t_{i}^{s}$ and $t_{j}^{s}$ are sequentially scheduled in the outbound truck sequence. If outbound trucks $t_{i}^{s}$ and $t_{j}^{s}$ have the same associate inbound trucks, then the sequences in sets $\mathrm{T}^{\mathrm{r}}, \mathrm{T}^{\mathrm{p}}$ and $\mathrm{T}^{\mathrm{n}}$ are modified based on one of the following two situations; i) outbound trucks $t_{i}^{s}$ and $t_{j}^{s}$ have in common only one associate inbound truck, ii) outbound trucks $t_{i}^{s}$ and $t_{j}^{s}$ have in common more than one associate inbound trucks.

First, if outbound trucks $t_{i}^{s}$ and $t_{j}^{s}$ have in common only one associate inbound truck $\mathrm{t}_{\mathrm{p}}^{\mathrm{r}}$ as presented on the left side of Figure 1 (a), then sequences in sets $\mathrm{T}^{\mathrm{r}}, \mathrm{T}^{\mathrm{y}}$ and $\mathrm{T}^{\mathrm{n}}$ can be modified as follows to decrese makespan.

1. In set $T^{\mathrm{r}}$, remove the associate inbound truck $\mathrm{t}_{\mathrm{p}}^{\mathrm{r}}$ of outbound truck $t_{j}^{s}$. Move the associate inbound truck $t_{p}^{r}$ of outbound truck $t_{i}^{s}$ to the last position of the associate inbound trucks for outbound truck $\mathrm{t}_{\mathrm{i}}^{\mathrm{s}}$.

2. In set $\mathrm{T}^{\mathrm{p}}$, move the product routing $\alpha_{\mathrm{pi}}$ to the corresponding position of $\mathrm{t}_{\mathrm{p}}^{\mathrm{r}}$ above. Move the product routing $\alpha_{\mathrm{pj}}$ to the position directly behind product routing $\alpha_{\mathrm{pi}}$.

3. In set $T^{\mathrm{n}}$, move $\beta_{\mathrm{pi}}$ and $\beta_{\mathrm{pj}}$ to the corresponding position of $\alpha_{\mathrm{pi}}$ and $\alpha_{\mathrm{pj}}$ above, respectively.

The modified sequences in sets $\mathrm{T}^{\mathrm{r}}, \mathrm{T}^{\mathrm{p}}$ and $\mathrm{Tn}$ are presented on the right side of Figure 1 (a). In this case, makespan will be decreased by the tuck change time of an outbound truck, D. If the the associate inbound truck $t_{p}^{r}$ of outbound truck $t_{i}^{s}$ is not moved to the last position of the associate inbound trucks for outbound truck $\mathrm{t}_{\mathrm{i}}^{\mathrm{s}}$, outbound truck $t_{i}^{s}$ needs to wait by $\beta_{p j}$ time units. Therefore, completion time of $t_{i}^{s}$ increase by $\beta_{p j}$ so that makespan only decreases by $\left(D-\beta_{\mathrm{pj}}\right)$ in this case. On the other hand, if the associate inbound truck $\mathrm{t}_{\mathrm{p}}^{\mathrm{r}}$ of outbound truck $t_{i}^{s}$ is moved to the last position of the associate inbound trucks for outbound truck $\mathrm{t}_{\mathrm{i}}^{\mathrm{s}}$ as presented above, outbound truck $t_{i}^{s}$ can immediately depart without waiting as soon as it loads $\alpha_{\text {pir }}$. Therefore, makespan will be decrease by $\mathrm{D}$ in this case.

Second, suppose that outbound trucks $t_{i}^{s}$ and $t_{j}^{s}$ 
have in common more than one associate inbound trucks $\mathrm{t}_{\mathrm{p}}^{\mathrm{r}}, \mathrm{t}_{\mathrm{c}}^{\mathrm{r}}, \mathrm{t}_{\mathrm{r}}^{\mathrm{r}}$ and $\mathrm{t}_{\mathrm{m}}^{\mathrm{r}}$ as as presented on the left side of Figure 1.

(b). Assume for explanation purposes that

$\beta_{\mathrm{pj}} \geq \beta_{\mathrm{qj}} \geq \mathrm{D}>\beta_{\mathrm{rj}} \geq \beta_{\mathrm{mj}}$ and

$\mathrm{t}_{\varepsilon^{\prime}}^{\mathrm{r}}=$ Inbound truck whose $\beta_{\varepsilon^{\prime} j}$ is the largest among the common associate inbound trucks (i.e. $\mathrm{t}_{\varepsilon^{i}}^{\mathrm{r}}=\mathrm{t}_{\mathrm{p}}^{\mathrm{r}}$ ). Then, the sequences in sets $\mathrm{T}^{\mathrm{r}}, \mathrm{T}^{\mathrm{p}}$ and $\mathrm{T}^{\mathrm{n}}$ can be modified as follows to decrese makespan.

1. In set $\mathrm{T}^{\mathrm{r}}$, remove all associate inbound trucks $t_{z}^{r}$ of outbound truck $t_{j}^{s}$ whose $\beta_{z j}$ is less than the truck change time among the common associate inbound trucks; (i.e. remove the associate inbound trucks $\mathrm{t}_{\mathrm{r}}^{\mathrm{r}}$ and $\mathrm{t}_{\mathrm{m}}^{\mathrm{r}}$ of outbound truck $t_{j}^{s}$ ). Remove the associate inbound truck $\mathrm{t}_{\varepsilon}^{\mathrm{r}}$ (i.e. $\mathrm{t}_{\mathrm{p}}^{\mathrm{r}}$ ) of outbound truck $\mathrm{t}_{\mathrm{j}}^{\mathrm{s}}$. Move the associate inbound truck $\mathrm{t}_{\varepsilon^{\prime}}^{\mathrm{r}}$ (i.e. $\mathrm{t}_{\mathrm{p}}^{\mathrm{r}}$ ) of outbound truck $t_{i}^{s}$ to the last associate inbound truck position for outbound truck $\mathrm{t}_{\mathrm{i}}^{\mathrm{s}}$.

2. In set $\mathrm{T}^{\mathrm{p}}$, move the product routing $\alpha_{\varepsilon^{\mathrm{i}}}$ (i.e. $\alpha_{\mathrm{pi}}$ ) to the corresponding position of $t_{\varepsilon}^{r}$ (i.e. $t_{p}^{r}$ ) above. Move the product routing $\alpha_{\varepsilon j}$ (i.e. $\alpha_{\mathrm{pj}}$ ) to the position next to product routing $\alpha_{\varepsilon \mathrm{i}}$ (i.e. $\alpha_{\mathrm{pi}}$ ).
Move all product routings $\alpha_{z j}$ whose $\beta_{z j}$ is less than the truck change time among the common associate inbound trucks (i.e. $\alpha_{\mathrm{rj}}$ and $\alpha_{\mathrm{mi}}$ ) to the position next to product routings $\alpha_{\mathrm{zi}}$ (i.e. $\alpha_{\mathrm{ri}}$ and $\alpha_{\mathrm{mi}}$, respectively.

3. In in set $\mathrm{T}^{\mathrm{n}}$, move $\beta_{\varepsilon^{\prime i}}$ and $\beta_{\varepsilon^{\prime j}}$ (i.e. $\beta_{\mathrm{pi}}$ and $\beta_{\mathrm{pj}}$ ) to the corresponding position of $\alpha_{\varepsilon^{i} i}$ and $\alpha_{\varepsilon^{\prime} j}$ (i.e. $\alpha_{\mathrm{pi}}$ and $\alpha_{\mathrm{pj}}$ ) above, respectively. Move all $\beta_{z \mathrm{j}}$, which are less than the truck change time among the common associate inbound trucks, (i.e. $\beta_{\mathrm{rj}}$ and $\beta_{\mathrm{mj}}$ ) to the corresponding position of product routings $\alpha_{\mathrm{zj}}$ (i.e. $\alpha_{\mathrm{rj}}$ and $\alpha_{\mathrm{mj}}$ ) above, respectively.

The modified sequences in sets $\mathrm{T}^{\mathrm{r}}, \mathrm{T}^{\mathrm{p}}$ and $\mathrm{T}^{\mathrm{n}}$ are presented on the right side of Figure 1 (b). In this case, makespan will be decreased by $\left[(\mu+1) D-\left(\sum_{\text {where } \beta_{z j}<D} \beta_{z j}\right)\right]$, whrere $\mu$ represents the number associate inbound trucks $\mathrm{t}_{\mathrm{z}}^{\mathrm{r}}$ of outbound truck $t_{j}^{s}$ whose $\beta_{z j}$ is less than the truck change time among the common associate inbound trucks and $\beta_{z j} \neq \beta_{\varepsilon^{j}}$.

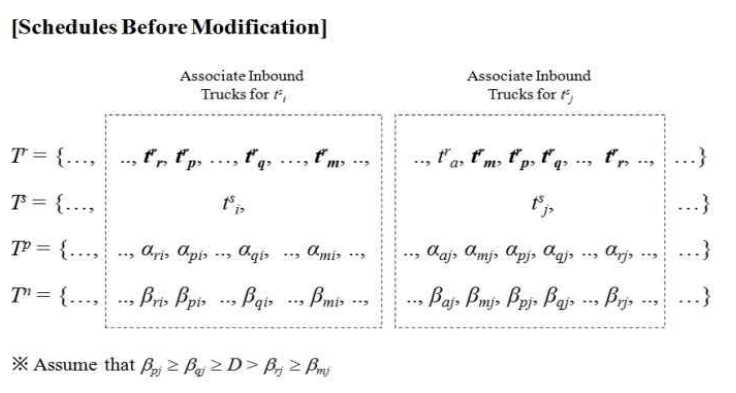

[Schedules After Modification]

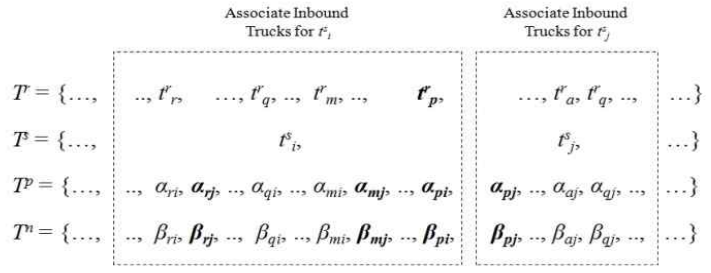

(a) Two consecutive outbound trucks have in common only one associate inbound truck

[Schedules Before Modification]

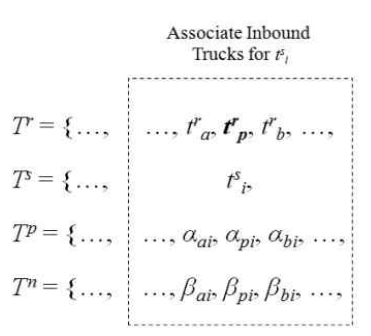

Associate Inbound Trucks for $t^{5}$,

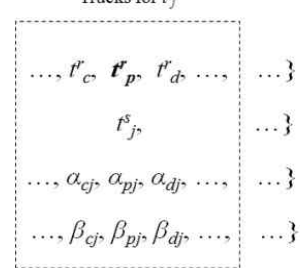

[Schedules After Modification]

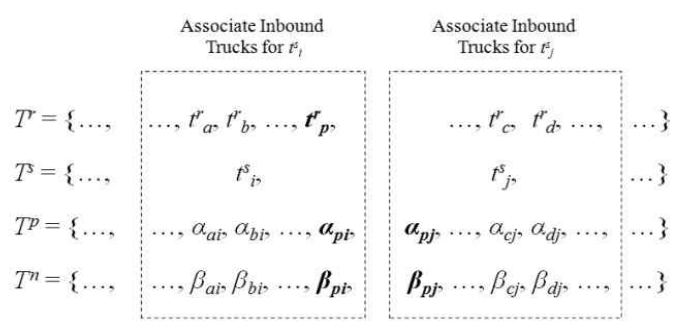

(b) Two consecutive outbound trucks have in common more than one associate inbound truck

[Figure 1] Modification of Schedules for Condition 1 Applied in Phase II 


\subsubsection{Condition 2 applied in Phase II}

This condition only applies to inbound trucks that appear more than once in the inbound truck sequence. Suppose the time required to unload products from the associate inbound truck $\mathrm{t}_{\mathrm{p}}^{\mathrm{r}}$ of outbound truck $t_{j}^{s}$ is less than the truck change time, D. Furthermore, suppose that the inbound truck $t_{p}^{r}$ as an associate of $t_{i}^{s}$ is already scheduled earlier in the inbound truck sequence before it is scheduled again as an associate inbound truck for outbound truck $t_{j}^{s}$. If the scheduling of the associate inbound truck $t_{p}^{r}$ of outbound truck $t_{i}^{s}$ was the last time $t_{p}^{r}$ was scheduled before it (i.e., $\mathrm{t}_{\mathrm{p}}^{\mathrm{r}}$ ) is scheduled again as an associate for outbound truck $t^{\mathrm{s}} \mathrm{j}$, then the sequences in sets $T^{\mathrm{r}}, \mathrm{T}^{\mathrm{p}}$ and $\mathrm{T}^{\mathrm{n}}$ may be modified based on one of the following two situations; i) the associate inbound truck $\mathrm{t}_{\mathrm{p}}^{\mathrm{r}}$ of outbound truck $\mathrm{t}_{\mathrm{j}}^{\mathrm{s}}$ unloads products only for outbound truck $\mathrm{t}_{\mathrm{j}}^{\mathrm{s}}$, ii) the associate inbound truck $\mathrm{t}_{\mathrm{p}}^{\mathrm{r}}$ of outbound truck $\mathrm{t}_{\mathrm{j}}^{\mathrm{s}}$ unloads products for more than one outbound truck $t_{j}^{s}$ when it comes into dock.

First, if inbound truck $\mathrm{t}_{\mathrm{p}}^{\mathrm{r}}$ appears in the inbound truck sequence as presented on the left side of Figure 2 (a) and $\beta_{\mathrm{pj}}<\mathrm{D}$, then sequences in sets $\mathrm{T}^{\mathrm{r}}$, $\mathrm{T}^{\mathrm{p}}$ and $\mathrm{T}^{\mathrm{n}}$ can be modified as follows to decrease makespan.

1. In set $T^{r}$, remove the associate inbound truck $\mathrm{t}_{\mathrm{p}}^{\mathrm{r}}$ of outbound truck $t^{\mathrm{s}}$.

2. In set $\mathrm{T}^{\mathrm{p}}$, move the product routing $\alpha_{\mathrm{pj}}$ to the position directly behind product routing $\alpha_{\mathrm{pi}}$.

3. In set $T^{\mathrm{n}}$, move $\beta_{\mathrm{pj}}$ to the corresponding position of $\alpha_{\mathrm{pj}}$ above.

The modified sequences in sets $\mathrm{T}^{\mathrm{r}}, \mathrm{T}^{\mathrm{p}}$ and $\mathrm{T}^{\mathrm{n}}$ are presented on the right side of Figure 2 (a). In this case, makespan will be decreased by $\left(\mathrm{D}-\beta_{\mathrm{p} j}\right)$.

Second, suppose that inbound truck $t_{p}^{r}$ unloads products for more than one outbound truck $t_{j}^{s}$ (i.e. $t_{j}^{\mathrm{s}}, t_{m}^{\mathrm{s}}$ and $t_{n}^{\mathrm{s}}$ ) when it comes into dock as presented on the left side of Figure 2 (b) and $\left(\beta_{\mathrm{pj}}+\beta_{\mathrm{pm}}+\beta_{\mathrm{pn}}\right)<$ D. Then, sequences in sets $T^{r}, T^{y}$ and $T^{n}$ can be modified as follows to decrease makespan.

1. In set $T^{r}$, remove the associate inbound truck $\mathrm{t}_{\mathrm{p}}^{\mathrm{r}}$ of outbound truck $\mathrm{t}_{\mathrm{j}}^{\mathrm{s}}$.

2. In set $\mathrm{T}^{\mathrm{p}}$, move the product routing $\alpha_{\mathrm{pj}}, \alpha_{\mathrm{pm}}$ and $\alpha_{\mathrm{pn}}$ to the position directly behind product routing $\alpha_{\mathrm{pi}}$.

3. In set $T^{\mathrm{n}}$, move $\beta_{\mathrm{p} j}, \beta_{\mathrm{pm}}$ and $\beta_{\mathrm{pn}}$ to the corresponding position of $\alpha_{\mathrm{p} j}, \quad \alpha_{\mathrm{pm}}$ and $\alpha_{\mathrm{pn}}$ above, respectively.

The modified sequences in sets $\mathrm{T}^{\mathrm{r}}, \mathrm{T}^{\mathrm{p}}$ and $\mathrm{T}^{\mathrm{n}}$ are presented on the right side of Figure 2 (b). In this case, makespan will be decreased by $\left[\mathrm{D}-\left(\beta_{\mathrm{pj}}+\beta_{\mathrm{pm}}{ }^{+}\right.\right.$ $\left.\left.\beta_{\mathrm{pn}}\right)\right]$.

With the two conditions for modification of the schedules as described above, the algorithmic steps of Phase II are as follows:

\section{STEP 1}

Take as inputs the outputs from Phase I algorithm. STEP 2

Starting from the beginning of the outbound truck sequence in set $T^{\mathrm{s}}$, sequentially investigate two consecutive outbound trucks, $t_{i}^{\mathrm{s}}$ and $t_{\mathrm{j}}^{\mathrm{s}}$, and their associate inbound trucks. If any two consecutive outbound trucks, $t_{i}^{s}$ and $t_{j}^{s}$, in the outbound truck sequence have the same associate inbound truck $\mathrm{t}_{\mathrm{p}}^{\mathrm{r}}$, modify the sequences in sets $\mathrm{T}^{\mathrm{r}}, \mathrm{T}^{\mathrm{p}}$ and $\mathrm{T}^{\mathrm{n}}$ as presented in section 4.2.1. Continue Step 2 until the last two consecutive outbound trucks in set $\mathrm{T}^{\mathrm{s}}$ are investigated.

\section{STEP 3}

Starting from the end of set $\mathrm{T}^{\mathrm{r}}$, check Condition 2 as presented in section 4.2.2. If Condition 2 is satisfied, modify the sequences in sets $\mathrm{T}^{\mathrm{r}}, \mathrm{T}^{\mathrm{p}}$ and $\mathrm{T}^{\mathrm{n}}$ as presented in section 4.2.2. Continue Step 3 until the first scheduled inbound truck in set $\mathrm{T}^{\mathrm{r}}$ is checked.

STEP 4

Stop; the best solution is found. Sets $T^{\mathrm{r}}, \mathrm{T}^{\mathrm{s}}, \mathrm{T}^{\mathrm{p}}$ and $\mathrm{T}^{\mathrm{n}}$ are the inbound truck sequence, outbound truck sequence, product routing, and the number of products transferred between inbound and outbound trucks, respectively.

As an illustration of Phase II algorithm, consider the Phase I solution (i.e., sequence sets (4)) described in Section 4.1 as the input of Phase II algorithm. After applying Phase II algorithm, the best solution for the example problem is as shown below in sequence sets (5). 
[Schedules Before Modification]

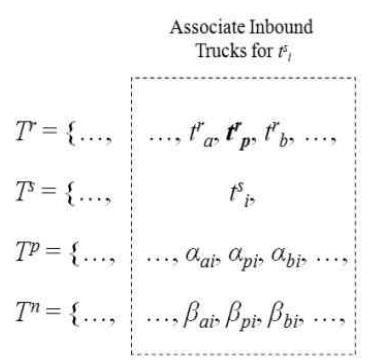

Associate Inbound Trucks for $t_{j}^{5}$

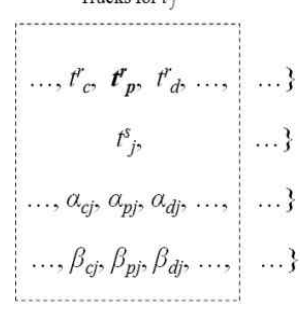

[Schedules After Modification]

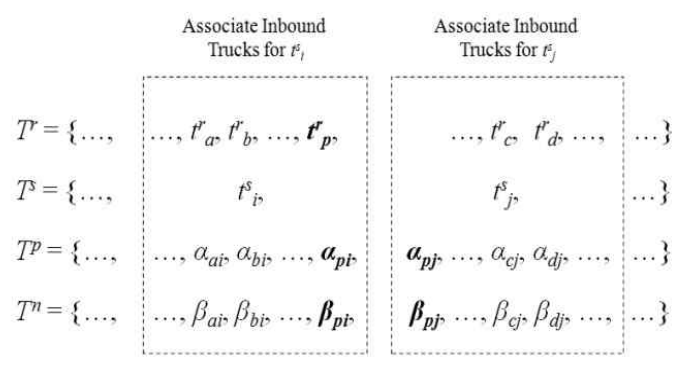

(a) Associate inbound truck $t_{p}^{r}$ of outbound truck $t_{j}^{s}$ unloads products only for outbound truck $t_{j}^{s_{j}}$
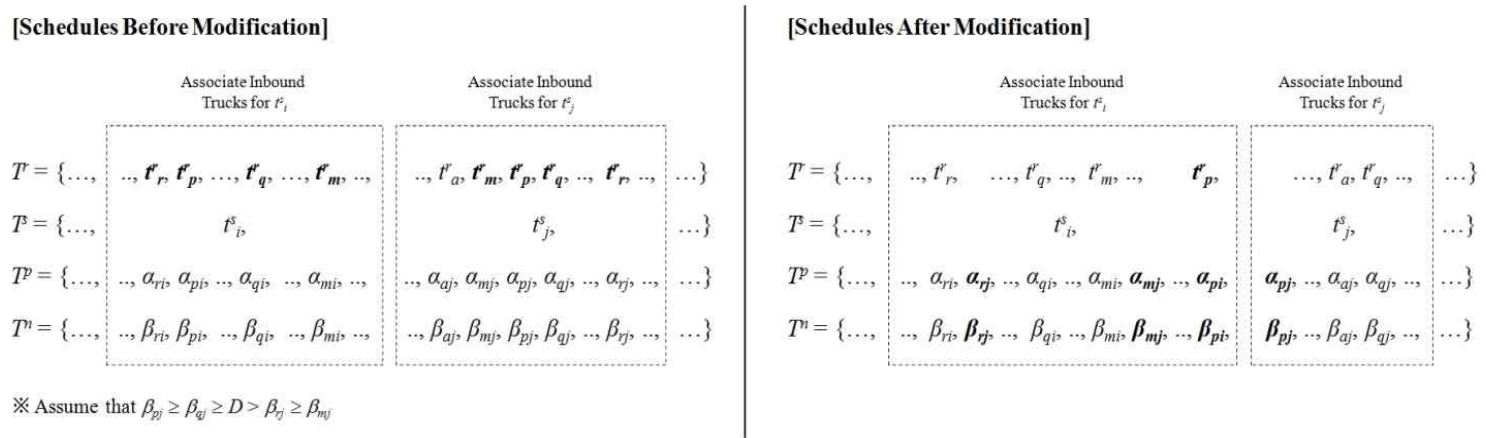

(a) Associate inbound truck $t_{p}^{r}$ of outbound truck $t_{j}^{s}$ unloads products only for outbound truck $t_{j}^{s}$

[Figure 2] Modification of Schedules for Condition 2 Applied in Phase II

\begin{tabular}{|c|c|}
\hline$T^{r}=\{$ & $t^{r}{ }_{4}$, \\
\hline$T^{s}=\{$ & $t^{5} 4$, \\
\hline$T^{p}=\{$ & $\alpha_{44}$, \\
\hline$T^{n}=$ & 80 , \\
\hline
\end{tabular}

$t_{5}{ }_{5}, \quad t_{2}{ }_{2}$

$\alpha_{51}, \alpha_{53}, \alpha_{21}$,

$131,4,50$,

\section{MAKESPAN}

The shortest completion time of a cross docking operation as described in this paper will occur when both inbound and outbound trucks visit the docks only once and no product is routed through the temporary storage. Thus, the lower bound to makespan, $\mathrm{LB}_{\mathrm{m}}$, can be calculated as in equation (6).

$$
L B_{m}=\max \left\{(R-1) D+\sum_{i=1}^{R} \sum_{k=1}^{N} r_{i k}+V, \quad(S-1) D+\sum_{j=1}^{S} \sum_{k=1}^{N} S_{j k}\right\}
$$

Suppose the Phase II final solution is represented as follows: let [i] be the inbound (outbound) truck in the $i^{\text {th }}$ sequence position in set $\mathrm{T}^{\mathrm{r}}\left(\mathrm{T}^{\mathrm{s}}\right)$. For the sets $\mathrm{T}^{\mathrm{p}}$ and $\mathrm{T}^{\mathrm{n}}$, let [i]' and [i]" refer to the inbound

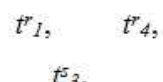

$\alpha_{23}, \alpha_{13}, \alpha_{12}, \alpha_{43}$, $51,166,14,115$,

$\left.\alpha_{42}, \alpha_{32}, \alpha_{52}, \alpha_{22}\right\}$

$35,190,85,59\}$ truck and the outbound truck involved in the $i^{\text {th }}$ sequence position, respectively. Then the Phase II final solution can be represented as in sequence sets (7).

\begin{tabular}{|c|c|c|c|c|c|c|}
\hline$T^{r}=\{$ & $t_{[1]}^{r}$, & $t_{[2]}^{r}$, & $t_{[3]}^{r}$, & $\ldots$ & $t^{r}[a-1]$, & $t^{r}[a]$ \\
\hline$T^{s}=\{$ & $t^{t_{[I]}}$ & $t^{s}[2]$, & $t^{5}[3]$ & $\ldots$ & $t^{5}[S-1]$ & $t^{t}[S]$ \\
\hline$T^{p}=\{$ & $\alpha_{[I][I],}$ & $\alpha_{[2][2]}$, & $\alpha_{[3][3] "}$ & $\ldots$ & $\alpha_{[b-1][b-1]}$ & $\left.\alpha_{[b][b]^{\prime \prime}}\right\}$ \\
\hline$T^{n}=\{$ & $\beta_{[I][I]}$, & $\beta_{[2][2] " ;}$ & $\beta_{[3]^{\prime}[3]^{\prime \prime}}$ & $\ldots$ & $\beta_{[b-1]^{\prime}(b-1]^{\prime \prime}}$ & $\beta_{[b]^{\prime}[b]}$ \\
\hline
\end{tabular}

Then makespan is calculated by finding two sets, $\mathrm{F}^{\mathrm{r}}$ and $\mathrm{F}^{\mathrm{s}}$ that contain task completion times, $\mathrm{\gamma}_{\mathrm{ij}}$ and $\delta_{\mathrm{i}}$, respeceively. Suppose that $F^{r}$ and $F^{s}$ can be represented as in sequence sets (8).

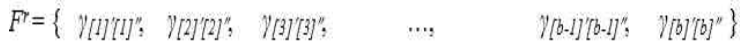

$$
\begin{aligned}
& F^{s}=\left\{\quad \delta_{[l],} \quad \delta_{[2],} \quad \delta_{[3],} \quad \ldots, \quad \delta_{[S-1],} \quad \delta_{[S]}\right\}
\end{aligned}
$$


To calculate makespan, the procedure first finds the completion time $\mathrm{Y}_{[i]^{\prime}\left[\mathrm{j}^{\prime \prime}\right.}$ in set $\mathrm{F}^{\mathrm{r}}$ of the inbound truck $\mathrm{t}_{[\mathrm{i}]}^{\mathrm{r}}$ associated with the product routing $\alpha_{[\mathrm{ij}]^{\prime} \mathrm{i}^{\mathrm{j}}}$ Next, the departure time, $\delta_{[i]}$, in set $F^{s}$ of the outbound truck $\mathrm{t}_{[\mathrm{i}]}^{\mathrm{s}}$ in the outbound truck sequence is found. The procedure for calculating makespan is presented below.

1. The inbound trucks unloading completion times

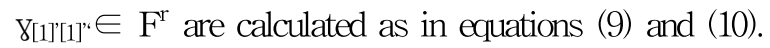

i) For the first element, $\left.\mathrm{y}_{[1]}[1]\right]^{\prime}$, in $\mathrm{F}^{\mathrm{r}}$.

$$
\gamma_{[I]}[I]^{\prime \prime}=\beta_{[I]^{\prime}[1]^{\prime \prime}}
$$

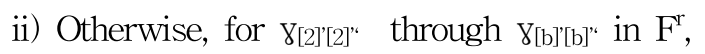

$$
\begin{array}{ll}
\left.\gamma_{[i]}[i]^{\prime \prime}=\gamma_{[i-1]}\right]^{\prime}[i-1]^{\prime \prime}+\beta_{[i]^{\prime}[i]^{\prime \prime},} & \text { if }[i]^{\prime}=[i-1]^{\prime} \\
\gamma_{[i]^{\prime}[i]^{\prime \prime}}=\gamma_{[i-1]]^{\prime}[i-]^{\prime \prime}}+D+\beta_{[i]^{\prime}[i]^{\prime \prime},} & \text { if }[i]^{\prime} \neq[i-1]^{\prime}
\end{array}
$$

Equation (10a) represents the case where there is no change in inbound truck while equation (10b) involves an inbound truck change.

2. To find the loading completion or departure times $\delta_{[i]} \in \mathrm{F}^{\mathrm{s}}$ of the outbound trucks corresponding to the outbound truck sequence $\mathrm{T}^{\mathrm{s}}$, the last position of the product routing $\alpha_{\mathrm{ij}} \in \mathrm{T}^{\mathrm{p}}$ associated with the outbound trucks in $\mathrm{T}^{\mathrm{s}}$ must be identified first. Suppose that the last product routing associated

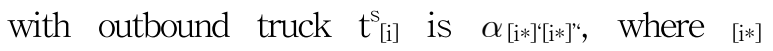
represents the position of the last product routing associated with outbound truck $\mathrm{t}_{[\mathrm{i}]}^{\mathrm{s}}$. Then, $\delta_{[\mathrm{i}]} \in \mathrm{F}^{\mathrm{s}}$ is calculated as follows: i) For the first element, $\delta_{[1]} \in \mathrm{F}^{\varsigma}$ corresponding to the first scheduled outbound truck $\mathrm{t}_{[1]}^{\mathrm{s}}$ is as in equation (11).

$$
\delta_{[1]}=\gamma_{\left[I^{*}\right]\left[I^{*}\right]^{\prime \prime}}+V
$$

ii) Otherwise, for all other elements $\delta_{[i]} \in \mathrm{F}^{\mathrm{s}}$, $2 \leq \mathrm{i} \leq \mathrm{S}$, corresponding to outbound truck $\mathrm{t}^{\mathrm{s}}{ }_{[\mathrm{i}]}$,

$$
\delta_{[i]}=\max \left\{\gamma_{\left[i^{*}\right]\left[i^{*}\right]^{n}}+V, \delta_{[i-1]}+D+\sum_{k=1}^{N} s_{[i] k}\right\}
$$

where $\sum_{k=1}^{N} s_{[i] k}$ is the loading time for all needed products for the outbound truck (i.e. $\mathrm{t}_{[\mathrm{i}]}^{\mathrm{s}}$ ).

3. Finally, the time it takes to complete all the cross docking activities is the makespan, $\mathrm{T}$, where

$$
T=\delta_{[S]} \quad \text { or } \quad T=\max _{[i]}\left\{\delta_{[i]}\right\}
$$

where $\delta_{[\mathrm{S}]}$ is the departure or loading completion time of the last scheduled outbound truck, $\mathrm{t}^{\mathrm{s}}$ [S] .

To illustrate the calculation of makespan, consider the solution given in sequence sets (5) for the example problem. Let truck change time equal 20 time units and the material transfer time of products from the receiving to the shipping dock equal 10 time units.

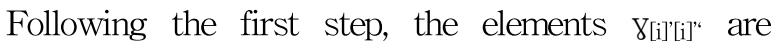
calculated as summarized below.

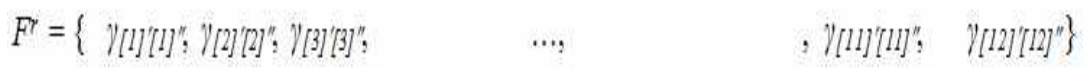

$$
\begin{aligned}
& =\left\{\gamma_{44}, \gamma_{51}, \quad \gamma_{53}, \quad \gamma_{21}, \gamma_{23}, \gamma_{13}, \gamma_{12}, \gamma_{43}, \gamma_{42}, \gamma_{32}, \gamma_{52}, \quad \gamma_{22}\right\} \\
& =\{80,231,235,305,356,542,556,691,726,936, \quad 1041, \quad 1120\}
\end{aligned}
$$

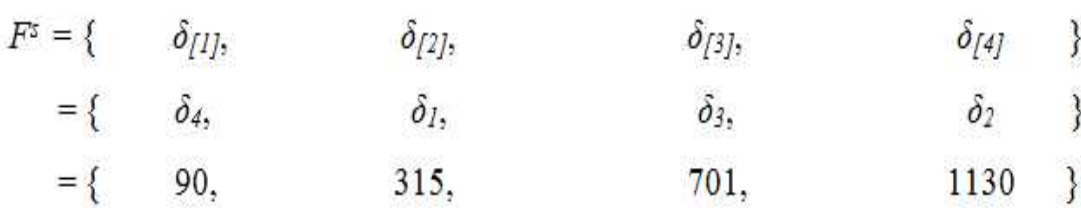


Next, the departure times of the outbound trucks are calculated as summarized below following the second step.

Finally, the makespan equals 1,130 , the departure time of the last scheduled outbound truck $2\left(=\delta_{[4]}=\delta_{2}\right)$. The lower bound, $\mathrm{LBm}=1070$.

\section{TESTING AND ANALYSIS}

Twenty sets of test problems presented by $\mathrm{Yu}$ and Egbelu [1] are used to assess the performances of the heuristic algorithms based on dispatching strategies. Having failed in the effort to find optimal solutions to the test problems as presented by $\mathrm{Yu}$ [23], another alternative to benchmark the performances of the heuristics was pursued using the lower bound, LBm, and the optimal solutions of the closely related cross docking model presented by $\mathrm{Yu}$ and Egbelu [1].

The model developed by $\mathrm{Yu}$ and Egbelu [1] (hereafter refered to as a 'Y\&E model') is similar to the model addressed in this paper except that it differs in some assumptions. Similar to the present model, Y\&E model assumes there is a temporary storage at the shipping dock; however it does not allow repeat visits to docks by trucks. So, the present model is a less contrained model than Y\&E model. With less contraints, the optimal solution to the present model should be as good as or better than that of $\mathrm{Y} \& \mathrm{E}$ model. So, in this respect the solutions to Y\&E model could serve as upper bounds to the current model. Therefore, one would expect the heuristic solution to the present model to be better or not significantly worse than the optimal solutions to Y\&E model for the same problem instance.

In all twenty test problem instances, the loading and unloading times are assumed to be the same for all products and are assumed to be one time unit in duration and the transfer time of products from the receiving dock to shipping dock through a set of conveyors is 100 time units. To test the heuristic algorithms, two different truck change times were used since the optimal solution is affected by the truck change time. Truck change times of 75 and 15 time units were respectively employed to assess the performances of the heuristics against the lower bound and the solutions of Y\&E model.

Tables 2 and 3 present the solutions to the test problems using 75 and 15 time units for truck change time, respectively. The tables show the lower bound, the optimal solutions to Y\&E model, the heuristics solutions associated with the three dispatching strategies of Phase I algorithm, and the solution from the compound heuristic. The "compound" heuristic is simply a heuristic that integrates the three inbound truck selection strategies into one heuristic (i.e. returns the best result found by any of the three strategies). From Table 2, the following results can be observed:

Across test problems and all heuristics, the actual solutions were higher than the lower bounds.

In 13 out of the 20 test problems, the compound heuristic found solutions that were better than the optimal solutions obtained by Y\&E model. The heuristic and Y\&E model found the same optimal solution in one problem instance (problem set 15). In six out of 20 test problems, the optimal solutions for Y\&E model were better than the solutions found by the compound heuristic, although not significantly. This level of performance points to the effectiveness of the heuristic in finding solution to the present model.

Among the three dispatching strategies for selecting inbound trucks, the third strategy (i.e. maximum fitness) found the best solution in 15 out of 20 problems. The first strategy (i.e. maximum flow) found the best solution in six problems and the second strategy (i.e. maximum ratio) found the best in eleven problems. The above counts indicate that there are problems in which the best solutions were found by more than one strategy. 
Table 2. Makespans of the Optimal Solutions for the Problem developed by Yu and Egbelu (2008) and the Heuristic Solutions for the Cross Docking Problem where Truck Change Time is 75

\begin{tabular}{|c|c|c|c|c|c|c|}
\hline \multirow{2}{*}{$\begin{array}{l}\text { Problem } \\
\text { Number }\end{array}$} & \multirow{2}{*}{$\begin{array}{l}\text { Lower } \\
\text { Bound }\end{array}$} & \multirow{2}{*}{$\begin{array}{l}\text { Optimal } \\
\text { Solution by } \\
\text { Y\&E Model }\end{array}$} & \multicolumn{4}{|c|}{ Cross Docking Heuristics } \\
\hline & & & Strategy 1 & Strategy 2 & Strategy 3 & Compound \\
\hline 1 & 1315 & 1557 & 1509 & 1532 & 1480 & 1480 \\
\hline 2 & 1430 & 1577 & 1683 & 1580 & 1580 & 1580 \\
\hline 3 & 1140 & 1372 & 1354 & 1354 & 1354 & 1354 \\
\hline 4 & 1400 & 1749 & 1940 & 1860 & 1912 & 1860 \\
\hline 5 & 1360 & 1579 & 1484 & 1484 & 1484 & 1484 \\
\hline 6 & 1345 & 1546 & 1497 & 1497 & 1495 & 1495 \\
\hline 7 & 1380 & 1535 & 1549 & 1510 & 1510 & 1510 \\
\hline 8 & 1190 & 1525 & 1461 & 1461 & 1451 & 1451 \\
\hline 9 & 1225 & 1473 & 1443 & 1415 & 1440 & 1415 \\
\hline 10 & 1180 & 1452 & 1399 & 1399 & 1399 & 1399 \\
\hline 11 & 2020 & 2232 & 2320 & 2320 & 2263 & 2263 \\
\hline 12 & 2425 & 2833 & 2800 & 2725 & 2725 & 2725 \\
\hline 13 & 2010 & 2386 & 2330 & 2405 & 2526 & 2330 \\
\hline 14 & 2080 & 2385 & 2392 & 2334 & 2380 & 2334 \\
\hline 15 & 2505 & 2745 & 2802 & 2906 & 2745 & 2745 \\
\hline 16 & 2090 & 2407 & 2574 & 2540 & 2465 & 2465 \\
\hline 17 & 1505 & 1867 & 1805 & 1805 & 1730 & 1730 \\
\hline 18 & 2245 & 2502 & 2620 & 2620 & 2695 & 2620 \\
\hline 19 & 2120 & 2553 & 2495 & 2495 & 2495 & 2495 \\
\hline 20 & 2495 & 2732 & 2938 & 3066 & 2863 & 2863 \\
\hline
\end{tabular}

For the results in Table 3 , the following characteristics are observed.

1. The lower bounds calculated were lower than the corresponding heuristic solutions across all heuristic.

2. The compound heuristic solutions were better than the optimal solutions obtained from $\mathrm{Y} \& \mathrm{E}$ model in all twenty test problems. The heuristic performance relative to the optimal solutions of Y\&E model is consistent with the less constrained nature of the present model. This confirms the effectiveness of the heuristic in solving the present model. The results are also consistent with the upper bound claim made earlier of the solutions to Y\&E model.

3. Of the three dispatching strategies, the third strategy (i.e. maximum fitness) found the best solution in sixteen test problems. The first strategy (i.e. maximum flow) found the best solution in ten problems and the second strategy (i.e. maximum ratio) found the best results in twelve problems. 
Table 3. Makespans of the Optimal Solutions for the Problem developed by Yu and Egbelu (2008) and the Heuristic Solutions for the Cross Docking Problem where Truck Change Time is 15

\begin{tabular}{|c|c|c|c|c|c|c|}
\hline \multirow{2}{*}{$\begin{array}{c}\text { Problem } \\
\text { Number }\end{array}$} & \multirow{2}{*}{ Lower } & \multirow{2}{*}{$\begin{array}{c}\text { Optimal Solution } \\
\text { by Y\&E Model }\end{array}$} & \multicolumn{5}{|c|}{ Cross Docking Heuristics } \\
\cline { 4 - 7 } & 1135 & 1257 & 1195 & 1195 & 1195 & 1195 \\
\hline 1 & 1190 & 1321 & 1250 & 1250 & 1235 & 1235 \\
\hline 2 & 1192 & 1065 & 1065 & 1065 & 1065 \\
\hline 3 & 1020 & 1389 & 1295 & 1265 & 1295 & 1265 \\
\hline 4 & 1160 & 1279 & 1180 & 1180 & 1180 & 1180 \\
\hline 5 & 1120 & 1306 & 1225 & 1225 & 1210 & 1210 \\
\hline 6 & 1165 & 1251 & 1200 & 1200 & 1200 & 1200 \\
\hline 7 & 1140 & 1225 & 1095 & 1095 & 1095 & 1095 \\
\hline 8 & 1020 & 1232 & 1105 & 1105 & 1105 & 1105 \\
\hline 9 & 1045 & 1212 & 1120 & 1120 & 1120 & 1120 \\
\hline 10 & 1060 & 1932 & 1840 & 1840 & 1855 & 1840 \\
\hline 11 & 1780 & 2473 & 2245 & 2230 & 2215 & 2215 \\
\hline 12 & 2125 & 1825 & Strategy 2 & Strategy 3 & Compound \\
\hline 13 & 1770 & 2026 & 1875 & 1875 & 1890 & 1875 \\
\hline 14 & 1840 & 2025 & 1945 & 1960 & 1930 & 1930 \\
\hline 15 & 2205 & 2385 & 2302 & 2295 & 2280 & 2280 \\
\hline 16 & 1850 & 2047 & 1985 & 1985 & 1970 & 1970 \\
\hline 17 & 1325 & 1585 & 1385 & 1385 & 1385 & 1385 \\
\hline 18 & 1945 & 2142 & 2065 & 2035 & 2050 & 2035 \\
\hline 19 & 1880 & 2253 & 1985 & 1985 & 1970 & 1970 \\
\hline 20 & 2195 & 2432 & 2360 & 2345 & 2330 & 2330 \\
\hline
\end{tabular}

To further analyze the performances of the heuristics relative to the optimal solutions derived from applying Y\&E model to the test problems, the "percentage deviation of makespan" was devised. Percentage deviation is defined as given below in equation (14).

Table 4 presents the percentage deviation of makespan when 75 and 15 units of time are used for truck change time, respectively. As can be seen in Table 4 , the average percentage deviation between the optimal solutions employing Y\&E model and the compound heuristic solution for the same problem instances is $-1.39 \%$ where truck change time is 75 . This implies that the compound heuristic solutions are, on average, better than the optimal solutions under Y\&E model. The average percentage deviations for dispatching strategies 1,2 and 3 for the problems relative to $\mathrm{Y} \& \mathrm{E}$ model are $0.57 \%$, $0.13 \%$ and $-0.49 \%$, respectively. These values indicate that every heuristic algorithm found solutions that were very close to the optimal solutions for Y\&E model.

$$
\left(\begin{array}{c}
\text { Percent Deviation } \\
\text { of Makespan }(\%)
\end{array}\right)=\frac{\text { (Makespan for Heurisitc Solution)- (Makespan for Optimal Solution obtained by Y\&E Model) }}{\text { Makespan for Optimal Solution obtained by Y\&E Model }} \times 100
$$


Table 4. Percentage Deviation of Makespan between the Optimal Solutions for the Problem developed by Yu and Egbelu (2008) and the Heuristic Solutions for the Cross Docking Problem

\begin{tabular}{|c|c|c|c|c||c|c|c|c|}
\hline \multirow{2}{*}{$\begin{array}{c}\text { Problem } \\
\text { Number }\end{array}$} & \multicolumn{2}{|c|}{75 Time Unit of Truck Change Time } & \multicolumn{3}{|c|}{15 Time Unit of Truck Change Time } \\
\cline { 2 - 8 } & $\begin{array}{c}\text { Strategy } \\
1\end{array}$ & $\begin{array}{c}\text { Strategy } \\
\text { Strategy }\end{array}$ & $\begin{array}{c}\text { Compoun } \\
\mathrm{d}\end{array}$ & $\begin{array}{c}\text { Strategy } \\
1\end{array}$ & $\begin{array}{c}\text { Strategy } \\
2\end{array}$ & $\begin{array}{c}\text { Strategy } \\
3\end{array}$ & $\begin{array}{c}\text { Compoun } \\
\mathrm{d}\end{array}$ \\
\hline 1 & $-3.08 \%$ & $-1.61 \%$ & $-4.95 \%$ & $-4.95 \%$ & $-4.93 \%$ & $-4.93 \%$ & $-4.93 \%$ & $-4.93 \%$ \\
\hline 2 & $6.72 \%$ & $0.19 \%$ & $0.19 \%$ & $0.19 \%$ & $-5.37 \%$ & $-5.37 \%$ & $-6.51 \%$ & $-6.51 \%$ \\
\hline 3 & $-1.31 \%$ & $-1.31 \%$ & $-1.31 \%$ & $-1.31 \%$ & $-10.65 \%$ & $-10.65 \%$ & $-10.65 \%$ & $-10.65 \%$ \\
\hline 4 & $10.92 \%$ & $6.35 \%$ & $9.32 \%$ & $6.35 \%$ & $-6.77 \%$ & $-8.93 \%$ & $-6.77 \%$ & $-8.93 \%$ \\
\hline 5 & $-6.02 \%$ & $-6.02 \%$ & $-6.02 \%$ & $-6.02 \%$ & $-7.74 \%$ & $-7.74 \%$ & $-7.74 \%$ & $-7.74 \%$ \\
\hline 6 & $-3.17 \%$ & $-3.17 \%$ & $-3.30 \%$ & $-3.30 \%$ & $-6.20 \%$ & $-6.20 \%$ & $-7.35 \%$ & $-7.35 \%$ \\
\hline 7 & $0.91 \%$ & $-1.63 \%$ & $-1.63 \%$ & $-1.63 \%$ & $-4.08 \%$ & $-4.08 \%$ & $-4.08 \%$ & $-4.08 \%$ \\
\hline 8 & $-4.20 \%$ & $-4.20 \%$ & $-4.85 \%$ & $-4.85 \%$ & $-10.61 \%$ & $-10.61 \%$ & $-10.61 \%$ & $-10.61 \%$ \\
\hline 9 & $-2.04 \%$ & $-3.94 \%$ & $-2.24 \%$ & $-3.94 \%$ & $-10.31 \%$ & $-10.31 \%$ & $-10.31 \%$ & $-10.31 \%$ \\
\hline 10 & $-3.65 \%$ & $-3.65 \%$ & $-3.65 \%$ & $-3.65 \%$ & $-7.59 \%$ & $-7.59 \%$ & $-7.59 \%$ & $-7.59 \%$ \\
\hline 11 & $3.94 \%$ & $3.94 \%$ & $1.39 \%$ & $1.39 \%$ & $-4.76 \%$ & $-4.76 \%$ & $-3.99 \%$ & $-4.76 \%$ \\
\hline 12 & $-1.16 \%$ & $-3.81 \%$ & $-3.81 \%$ & $-3.81 \%$ & $-9.22 \%$ & $-9.83 \%$ & $-10.43 \%$ & $-10.43 \%$ \\
\hline 13 & $-2.35 \%$ & $0.80 \%$ & $5.87 \%$ & $-2.35 \%$ & $-7.45 \%$ & $-7.45 \%$ & $-6.71 \%$ & $-7.45 \%$ \\
\hline 14 & $0.29 \%$ & $-2.14 \%$ & $-0.21 \%$ & $-2.14 \%$ & $-3.95 \%$ & $-3.21 \%$ & $-4.69 \%$ & $-4.69 \%$ \\
\hline 15 & $2.08 \%$ & $5.87 \%$ & $0.00 \%$ & $0.00 \%$ & $-3.48 \%$ & $-3.77 \%$ & $-4.40 \%$ & $-4.40 \%$ \\
\hline 16 & $6.94 \%$ & $5.53 \%$ & $2.41 \%$ & $2.41 \%$ & $-3.03 \%$ & $-3.03 \%$ & $-3.76 \%$ & $-3.76 \%$ \\
\hline 17 & $-3.32 \%$ & $-3.32 \%$ & $-7.34 \%$ & $-7.34 \%$ & $-12.62 \%$ & $-12.62 \%$ & $-12.62 \%$ & $-12.62 \%$ \\
\hline 18 & $4.72 \%$ & $4.72 \%$ & $7.71 \%$ & $4.72 \%$ & $-3.59 \%$ & $-5.00 \%$ & $-4.30 \%$ & $-5.00 \%$ \\
\hline 19 & $-2.27 \%$ & $-2.27 \%$ & $-2.27 \%$ & $-2.27 \%$ & $-11.90 \%$ & $-11.90 \%$ & $-12.56 \%$ & $-12.56 \%$ \\
\hline 20 & $7.54 \%$ & $12.23 \%$ & $4.80 \%$ & $4.80 \%$ & $-2.96 \%$ & $-3.58 \%$ & $-4.19 \%$ & $-4.19 \%$ \\
\hline Average & $0.57 \%$ & $0.13 \%$ & $-0.49 \%$ & $-1.39 \%$ & $-6.86 \%$ & $-7.08 \%$ & $-7.21 \%$ & $-7.43 \%$ \\
\hline
\end{tabular}

With 15 time units for truck change time, the percentage deviations from makespan relative to Y\&E model are also reported in Table 4. The superiority of the heuristic solutions to the optimal solutions by Y\&E model is clearly seen from the table. Comparing two truck change times, it is evident that the developed heuristic solutions is more superior to the Y\&E model as truck change time decreases. This is expected since it is preferable to incure the delay due to truck change time than to route the products to the temporary buffer if truck change time is relatively small. Of the three selection strategies, the average percentage deviation for strategy 3 (maximum fitness) are the lowest in all cases regardless of truck change time. On the weak side, it also recorded the worst deviation of 9.32\% (see problem 4 in Table 4). Therefore, to get the best of the three strategies and guard against inferior solution, the use of the compound algorithm is recommended.

\section{CONCLUSION}

With the objective to minimize makespan, the cross docking problem addressed in this paper allows trucks to pull in and out of the docks as many times as considered profitable until all their loading and unloading needs are completely satisfied. To solve the problem, the heuristic approaches based on three dispatching strategies were developed. Due to computational time intensity with the mixed integer programming approach as the size of a problem increases as presented by $\mathrm{Yu}$ [23], ultimately, it was the heuristic approaches that were used. 
With the optimal solutions to the test problems not available, the lower bounds to the problems and the solutions to the closely related model to the present model were instead used to benchmark the performance of the heuristics. Because the closely related model was more constrained than the present model, their optimal solutions served as pseudo upper bounds for the same problem instances.

The results of the comparison based on the test problems showed that when the heuristics based on three dispatching strategies developed are integrated into a single heuristic, referred to as a compound heuristic, the compound heuristic produced solutions that are, on average, $1.39 \%$ better than those obtained under the closely related model when truck change time is 75 time units. Similarly, the average percentage improvement in solution becomes $7.43 \%$ when truck change time becomes 15 time units based on Y\&E model. This confirms the claim that the optimal solutions to the $\mathrm{Y} \& \mathrm{E}$ model can serve as upper bounds to the optimum solution to the more relaxed model addressed in this paper. In general, the compound heuristic found solutions below the upper bound and thus demonstrates its effectiveness as a viable solution algorithm. The results show that the compound heuristic is more superior to the Y\&E model as truck change time decreases. The results also imply that the implementation of a flexible cross docking policy that allows trucks to make repeat visits to docks and allows items to be routed to temporary storage, when necessary, is superior to policies that remove these flexibilities either partially or fully.

\section{REFERENCES}

[1] Yu W, Egbelu JP. Scheduling of inbound and outbound trucks in cross docking systems with temporary storage. European Journal of Operational Research 2008; 184:377 - 96.

[2] Lee YH, Jung JW, Lee KM. Vehicle routing scheduling for cross-docking in the supply chain. Computers and Industrial Engineering 2006; 51:247 - 56.

[3] Ross A, Jayaraman V. An evaluation of new he uristics for the location of cross-docks distribution centers in supply chain network design. Computers and Industrial Engineering 2008; 55:64 - 79 .

[4] Liao C, Lin Y, Shih CS. Vehicle routing with cross-docking in the supply chain. Expert Systems with Applications 2010; 37:6868 - 73.

[5] Musa R, Arnaout JP, Jung H. Ant colony optimi zation algorithm to solve for the transportation problem of cross-docking network. Computers and Industrial Engineering 2010; 59:85-92.

[6] Gue RK. The effects of trailer scheduling on the layout of freight terminals. Transportation Science 1999; 33(4):419 - 28.

[7] Bartholdi JJ, Gue RK. The best shape for a crossdock. Transportation Science 2004; 38(2): $235-44$.

[8] Vis FAI, Roodbergen KJ. Positioning of goods in a cross-docking environment. Computers and Industrial Engineering 2008; 54:677 - 89.

[9] Oh Y, Hwang H, Cha CN, Lee S. A dock-door assignment problem for the Korean mail distribution center. Computers and Industrial Engineering 2006; 51:288 - 96.

[10] Bozer AY, Carlo JH Optimizing inbound and outbound door assignments in less-than-truck load crossdocks. IIE Transactions 2008; 40:1007-18.

[11] Miao Z, Lim A, Ma H. Truck dock assignment problem with operational time constraint within crossdocks. European Journal of Operational Research 2009; 192:105 - 15.

[12] Chen F, Song K Minimizing makespan in two-stage hybrid cross docking scheduling problem. Computers and Operations Research 2009; 36:2066 - 73 .

[13] Boysen N. Truck scheduling at zero-inventory cross docking terminals. Computers and Operations Research 2010; 37:32 - 41.

[14] Soltani R, Sadjadi SJ. Scheduling trucks in cross-docking systems: A robust meta-heuristics approach. Transportation Research Part E 2010; 46:650 - 66.

[15] Vahdani B, Zandieh M. Scheduling trucks in cross-docking systems: Robust meta-heuristics. Computers and Industrial Engineering 2010; $58: 12-24$ 
[16] Arabani ARB, Ghomi SMTF, Zandieh M. Meta -heuristics implementation for scheduling of trucks in a cross-docking system with temporary storage. Expert Systems with Applications 2011; 38:1964 - 79.

[17] Larbi R, Alpan G, Baptiste P, Penz B. Sche duling cross docking operations under full, partial and no information on inbound arrivals. Computers and Operations Research 2011; 38:889-900.

[18] Chen P, Guo Y, Lim A, Rodrigues B. Multiple cross docks with inventory and time windows. Computers and Operations Research 2006; 33:43 $-63$.

[19] Waller AM, Cassady CR, Ozment, J. Impact of cross-docking on inventory in a decentralized retail supply chain. Transportation Research Part E 2006; 42:359 - 382.

[20] Chen F, Lee C. Minimizing the makespan in a two-machine cross-docking flow shop problem. European Journal of Operational Research 2009; 193:59 - 72.

[21] Yan H, Tang S. Pre-distribution and postdistribution cross-docking operations. Transportation Research Part E 2009; 45:843 - 59.

[22] Boysen, N, Fliedner M. Cross dock scheduling: Classification, literature review and research agenda. Omega 2010; 38:413 - 22.

[23] Yu, W. Operational strategies for cross docking systems. Iowa State University. Ph.D. Dissertation; 2002.

\section{Author introduction}

Wooyeon $\mathrm{Yu}$

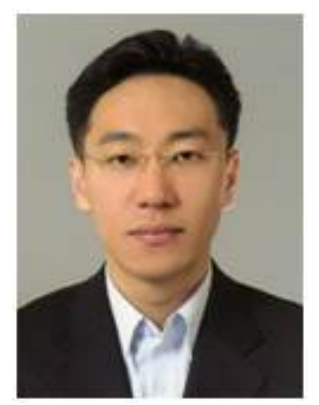

Wooyeon Yu received his Ph.D. degree in the Department of Industrial and Manufacturing Systems Engineering from Iowa State University. He is currently an associate professor in the Department of Industrial and Management Engineering at Myong Ji University in Korea. Before he joined Myong Ji University, he worked as a senior consultant at Samsung SDS. His primary research interests are in material handling, logistics and supply chain management.

Address: Department of Industrial and Management Engineering College of Engineering Myong Ji University San 38-2, Nam-Dong, Cheoin-Gu, Yongin Gyeonggi-Do, S.Korea 449-728
Pius J. Egbelu

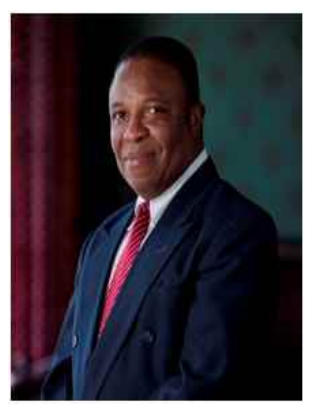

Pius J. Egbelu, $\mathrm{PhD}$, is dean of the NJIT School of Manageme nt and also holds the title of distinguished professor and Then \& Clark Chair. His research interests are in the areas of automated material handling, facilities planning and design, manufacturing, supply chain engineering and enterprise and service systems analysis. $\mathrm{He}$ is a Fellow of the Institute of Industrial Engineers and a licensed engineer in the State of Louisiana.

Address: School of Management New Jersey Institute of Technology University Heights Newark, New Jersey 07102 